\title{
Semen Quality in the General Population of Bulgaria
}

\author{
Vladislav Dobrinov', Desislava Tacheva',2, Magdalena Rangelova1, Milena Dobreva1, \\ Gergana Georgieva ${ }^{1}$, Iavor Vladimirov ${ }^{1,2}$
}

${ }^{1}$ IVF Unit, SBALAGRM-Sofia, Sofia, Bulgaria

${ }^{2}$ Faculty of Biology, Sofia University "St. Kliment Ohridski”, Sofia, Bulgaria

Email: dobrinovvladislav@gmail.com

How to cite this paper: Dobrinov, V., Tacheva, D., Rangelova, M., Dobreva, M., Georgieva, G. and Vladimirov, I. (2020) Semen Quality in the General Population of Bulgaria. Open Journal of Obstetrics and Gynecology, 10, 1-12.

https://doi.org/10.4236/ojog.2020.101001

Received: December 2, 2019

Accepted: December 23, 2019

Published: December 26, 2019

Copyright $\odot 2020$ by author(s) and Scientific Research Publishing Inc. This work is licensed under the Creative Commons Attribution International License (CC BY 4.0).

http://creativecommons.org/licenses/by/4.0/

(c) (i) Open Access

\begin{abstract}
Background: With the accumulating evidence of semen difference between distinct populations we decided to conduct a population-based prospective study to assess the reproductive capabilities of the Bulgarian males. Objective: To evaluate the semen parameters in men from the general population of Bulgaria. To analyze the effects of BMI (Body mass index) and tobacco smoking on semen characteristics. Methods: 482 males without history of reproductive problems were included for the purpose of this study. The duration of our study was from April to May in 2016 and April in 2017. The volunteers were subdivided based on their smoking status and on their BMI. After semen collection, a conventional semen analysis was carried out manually by trained embryologists in an andrology laboratory according to WHO recommendations. The results were statistically analyzed and presented with their mean values. Result(s): After semen analysis we report a mean of $3.29 \mathrm{ml}$ for semen volume, $40.68 \times 10^{6} / \mathrm{ml}$ for spermatozoa concentration, $128.38 \times 10^{6}$ for total sperm count, $52.54 \%$ of total motile spermatozoa in the ejaculate and a mean percentage of morphologically normal sperm standing at $9.6 \%$. We did not find a negative effect of tobacco smoking on semen quality; however higher BMI is associated with lower sperm concentration per ml. Discussion and Conclusion(s): This is the first contemporary study, assessing semen quality in Bulgarians. The results obtained here show the lower quality of semen in Bulgaria, compared to other countries. No statistical differences were found between the semen quality of nonsmokers and smokers. Higher BMI was found to be associated with lower sperm concentration per milliliter.
\end{abstract}

\section{Keywords}

Male Infertility, Semen Analysis, Sperm Concentration, Body Mass Index, Tobacco Smoking 


\section{Introduction}

It is a well-known fact that fertility decreases with the increase in age in both men and women. Since the advent of assisted reproductive technology (ART) people are becoming more and more dependent on these techniques in order to have offspring. This is due to the fact that various causes of infertility can be bypassed by the use of ART; however frequently the primary condition remains untreated. While female infertility has drawn more attention, it is proposed that 1 in 20 men are infertile on worldwide scale [1]. Moreover, the cause of infertility in about $20 \%-40 \%$ of infertile couples is attributed to the male partner [2]. This statement calls for more research regarding the possible causes of male infertility and how can we overcome them. From a medical point of view, it is important to reveal the exact cause of infertility as it could be due to some form of cancer, which if left untreated may affect not only patient's fecundity. On a personal level, infertility could cause potential psychological problems.

Semen quality is directly related to men's reproductive capabilities and there is accumulating evidence of the deterioration of semen parameters during the last 40 - 50 years [3]. This aggravation is connected to many various factors like smoking, stress, alcohol consumption, age and many others. Environmental toxins and dietary patterns could further worsen the quality of men's semen. Additionally, the higher incidence of testicular dysgenesis syndrome on a worldwide scale also impacts semen parameters negatively. Interestingly, in the literature have been reported differences between the semen parameters of men from different geographical regions [4]. And since this establishment, various studies have been published in order to assess different populations' seminal parameters [5] [6]. Even more interesting is the fact that these differences aren't well defined. Differences in style and quality of life in different countries, geographical peculiarities and many other factors all contribute to these differences. Virtanen et al. conducted a large meta-analysis in 2017 underlining the difference between semen parameters of men from different countries [7]. The study included many countries from all around the world; however there was no available data regarding Bulgaria. Moreover, we could not find any study reporting semen characteristics from the general population in Bulgaria in the last 30 years. Therefore, we decided to conduct a population-based prospective study with the goal of assessing semen quality in Bulgaria and to compare it to other publications on this topic. As a secondary goal we decided to analyze the role of $\mathrm{BMI}$ and tobacco smoking on semen parameters due to the fact that there isn't a unified answer on these topics.

\section{Materials and Methods}

\subsection{Patient Selection}

In order to recruit volunteers, we designed a campaign with the goal of assessing male's reproductive health in Bulgaria, based on semen analysis. The study was approved by the ethical committee of Sofia Hospital of Obstetrics, Gynaecology 
and Reproductive Medicine. No informed consent was needed for the conduction of this study according to the ethical committee. The duration of our study was from April to May in 2016 and April in 2017. The participants were Bulgarian volunteers, who wanted to have their semen tested, aged 18 - 55 with or without history of reproductive problems, coming from all parts of Bulgaria. All patients with potential or previously known reproductive issues were excluded, due to the fact that our goal was to assess healthy male's reproductive potential. We considered varicocele, various sexually transmitted diseases, cryptorchidism, epididymitis as conditions that may interfere with male's fertility while we also excluded patients recovering from surgeries and cancer treatments. Study inclusion criteria encompassed only men with unknown fertility status, undergoing semen analysis for the first time. From a total number of 621 patients who participated in the campaign, after applying our exclusion criteria, a final number of 482 patients without reproductive problems, but with unknown fertility status were selected. Further selection was made according to patient's smoking status and BMI. Before semen collection all patients were questioned about their medical reproductive history, lifestyle factors and sexual abstinence period. They were also questioned if they had consumed alcohol the day prior to semen collection and if they had used any antibiotics the past two weeks.

\subsection{Sample Collection and Analysis}

Semen samples were collected in plastic sterile containers by masturbation after a sexual abstinence period of 2 - 7 days. All semen samples were manually evaluated after 30 minutes of liquefaction at room temperature for volume, sperm concentration, morphology and motility while $\mathrm{pH}$ and the presence of leukocytes, sperm agglutination and aggregation were also noted, but not used in this study. The semen analysis was performed by trained embryologists in an andrology laboratory. All samples were analyzed within 1 hour after semen collection. The analysis was made according to the 5th WHO guidelines [8]. Semen volume was measured by the aspiration method and the results were presented as milliliters. Motility was expressed as a percentage of normokinetic, hypokinetic and immotile spermatozoa when at least 200 spermatozoa were analyzed. Total motility was calculated by adding the percentage of hypokinetic spermatozoa to the number of normokinetic ones. Sperm concentration was analyzed with Makler counting chamber (MICROPTIC) and was expressed as spermatozoa concentration per $\mathrm{ml}$ and total number of spermatozoa in the ejaculate calculated by multiplying semen volume $\mathrm{x}$ sperm concentration/ml. Sperm morphology was assessed according to Kruger's strict criteria and was analyzed using Testsimplets (Waldeck) prestained slides. At least 200 spermatozoa per sample were categorized as having abnormal or normal morphology when the final morphology was represented as a percentage. To define a sample with normal sperm morphology we used a cut-off value of $14 \%$ normal forms according to the 4th WHO guidelines from 1999 [9]. 


\subsection{Distribution of Cases}

Based on the results from the semen analysis we further divided the subjects. The distribution of cases was performed in line with WHO recommendations [8]. Therefore, a patient with a sperm concentration less than 15 million per milliliter was classified as having an Oligozoospermia. Azoospermia was defined as absence of spermatozoa in the ejaculate after centrifugation. Asthenozoospermia included samples with less than $32 \%$ normokinetic spermatozoa. Normozoospermia included samples with volume greater than $1.5 \mathrm{ml}$, sperm concentration per ml greater than 15 million, normokinetic spermatozoa more than $32 \%$ and more than $14 \%$ of morphologically normal forms. Cases, featuring combined abnormalities were classified by the aforementioned values.

\subsection{Statistical Analysis}

All statistical analysis was performed by GraphPad InStat and GraphPad Prism 6 . We calculated the mean, median (5th - 95th percentile) and standard deviation for all semen parameters based on the untransformed raw data. Semen parameters are not represented in median, but in mean data for convenience. We used Mann-Whitney $U$ test (two-tailed) when assessing the influence of tobacco smoking on the semen variables. Kruskal-Wallis test was used to compare the semen variables between the different BMI groups. Statistically significant differences were reported if $\mathrm{P}<0.05$.

\section{Results}

\subsection{Subject Characteristics}

The mean age of the 482 patients was 34.38 (SD 6.62). In order to analyze the effects of tobacco smoking and BMI on the semen parameters the participants were subdivided based on their smoking status and BMI. Unfortunately, we did not have complete information for the whole sample size and therefore we ended up with 203 nonsmokers and 73 smokers. In the BMI group we had 276 subjects which were further subdivided in three groups-104 patients with BMI < 24.9; 122 patients with BMI between 25 and 29.9; 50 patients with BMI $>30$.

\subsection{Semen Variables}

Semen parameters are presented in Table 1 based on the raw data. Mean semen volume was $3.29 \mathrm{ml}$ (SD 1.673). Mean sperm concentration per $\mathrm{ml}$ was 40.684 (SD 27.075) while the total sperm number in the ejaculate had a mean of 128.38 (105.4). Mean percentage of normokinetic spermatozoa was 44.71 (SD 13.181) while the hypokinetic percentage was 8.11 (SD 4.315). Total sperm motility expressed as a combination of normokinetic and hypokinetic spermatozoa had a mean value of 52.535 (SD 15.567). Sperm morphology according to Kruger's strict criteria and expressed as percentage normal forms had a mean value of 9.6 (SD 4.287). 
Table 1. Semen quality of healthy Bulgarian men.

\begin{tabular}{ccccccccc}
\hline $\begin{array}{c}\text { Total number } \\
\text { of patients } \\
\mathrm{N}=482\end{array}$ & $\begin{array}{c}\text { Age } \\
\text { (years) }\end{array}$ & $\begin{array}{c}\mathrm{V} \\
(\mathrm{ml})\end{array}$ & $\begin{array}{c}\text { Sperm } \\
\text { concentration } \\
\text { (million/ml) }\end{array}$ & $\begin{array}{c}\text { Total sperm } \\
\text { concentration } \\
\text { (million) }\end{array}$ & $\begin{array}{c}\text { Normokinesis } \\
(\%)\end{array}$ & $\begin{array}{c}\text { Hypokinesis } \\
(\%)\end{array}$ & $\begin{array}{c}\text { Total motility Morphology } \\
(\%)\end{array}$ \\
\hline Mean (SD) & 34.38 & 3.29 & 40.68 & 128.38 & 44.71 & 8.11 & 52.54 & 9.6 \\
& $(6.62)$ & $(1.673)$ & $(27.075)$ & $(105.4)$ & $(13.181)$ & $(4.315)$ & $(15.567)$ & $(4.287)$ \\
Median (5) & & 34 & 39 & 110.2 & 50 & 7 & 56.5 & 10 \\
$95^{\text {th }}$ percentile) & $(25-46)$ & $(1.2-6.5)$ & $(2-87)$ & $(4-329)$ & $(2-51)$ & $(2-15)$ & $(7-66)$ & $(3-15)$ \\
\hline
\end{tabular}

$\mathrm{SD}=$ standard deviation; $\mathrm{N}=$ number. Sperm morphology available for 470 subjects.

\subsection{Semen Abnormalities}

Figure 1 shows the distribution of cases based on the results from the semen analysis. Out of the 482 participants we found only 133 cases of Normozoospermia, comprising $27.59 \%$ of the whole sample size. Semen samples with only morphological anomalies (defined as Kruger's strict criteria test results between 5 and 13) were most commonly seen, encompassing $46.89 \%(\mathrm{~N}=226)$ of the total sample size. Patients with Teratozoospermia represented $4.77 \%(\mathrm{~N}=23)$. Oligoozoospermia was seen in $5.19 \%(\mathrm{~N}=25)$ of the subjects. Multiple abnormalities such as Oligoasthenoteratozoospermia $(\mathrm{N}=27)$ represented 5.60\%; Oligoteratozoospermia-4.56\% $(\mathrm{N}=22)$; Oligoasthenozoospermia $(\mathrm{N}=$ 3) $-2.70 \%$. Complete lack of spermatozoa in the ejaculate, defined as Azoospermia was present in $1.66 \%(\mathrm{~N}=8)$ of the subjects. Asthenozoospermia constituted $1.04 \%(\mathrm{~N}=5)$.

\subsection{Tobacco Smoking and Semen Characteristics}

Descriptive statistics from patients separated by their smoking status is presented in Table 2. We found a higher number of total sperm concentration and concentration per milliliter in the nonsmokers group compared to the smokers' one. Despite this fact, when comparing the results, we found no statistically significant difference between the two groups $(\mathrm{P}>0.05)$. Other semen characteristics showed very subtle distinction.

\subsection{BMI and Semen Characteristics}

Patients were allocated in three groups according to their BMI. Group 1 included 104 patients with BMI < 24.9; Group 2 - 122 patients with BMI between 25 and 29.9; 50 Subjects with BMI > 30 were allocated in Group 3. There were some differences between groups' mean semen volume, motility and morphology (Table 3). The most substantial differences between groups were seen when comparing sperm concentration per $\mathrm{ml}$ and total sperm concentration. It was found that there is a significant statistical difference between sperm concentration per $\mathrm{ml}$ between the different BMI groups $(\mathrm{P}=0.037)$. Although the obvious difference in total sperm concentration, statistical significance was not reported. Additionally, we found no significant difference when comparing other semen characteristics $(\mathrm{P}>0.05)$. 


\section{SEMEN ABNORMALITIES}



Figure 1. Distribution of cases based on the results from the 482 semen analysis. Distribution was made according to WHO 5th edition guidelines. Morphological anomalies refer to semen samples with Kruger's strict criteria test result value between 5 and 13 .

Table 2. Influence of tobacco smoking on semen characteristics.

\begin{tabular}{cccc}
\hline Parameters & $\begin{array}{c}\text { Smokers } \\
(\mathbf{N}=73)\end{array}$ & $\begin{array}{c}\text { Non-smokers } \\
(\mathbf{N}=203)\end{array}$ & P-value \\
\hline Age (years) & 35.32877 & 34.03941 & $>0.05$ \\
(SD) & $(6.227)$ & $(7.13)$ & \\
Volume (ml) & 3.39863 & 3.317734 & $>0.05$ \\
(SD) & $(2.018)$ & $(1.563)$ & \\
Sperm concentration (million/ml) & 35.08904 & 39.90395 & $>0.05$ \\
(SD) & $(22.041)$ & $(25.457)$ & \\
Total sperm concentration (million) & 112.2897 & 128.7916 & $>0.05$ \\
(SD) & $(89.658)$ & $(103.43)$ & \\
Normokinesis (\%) & 45.55556 & 45.0198 & $>0.05$ \\
(SD) & $(12.197)$ & $(13.027)$ & \\
Hypokinesis (\%) & 7.657534 & 7.615764 & $>0.05$ \\
(SD) & $(4.059)$ & $(4.579)$ & \\
Total motility (\%) & 52.35616 & 52.27094 & $>0.05$ \\
(SD) & $(15.15)$ & $(15.292)$ & \\
Morphology (\%) & 9.638889 & 9.772727 & $>0.05$ \\
(SD) & $(4.329)$ & $(4.79)$ & \\
\hline
\end{tabular}

Mann-Whitney U test (two-tailed) was used for comparison between groups. SD = standard deviation; $\mathrm{N}=$ number.

Table 3. Effect of BMI on semen parameters.

\begin{tabular}{ccccc}
\hline & Group 1 & Group 2 & Group 3 & \\
Parameter & $<24.9$ & $25-29.9$ & $>30$ & P value \\
& $\mathrm{N}=104$ & $\mathrm{~N}=122$ & $\mathrm{~N}=50$ & \\
\hline Volume (ml) & 3.4 & 3.3 & 3.3 & \\
$(\mathrm{SD})$ & $(1.7)$ & $(1.7)$ & $(1.7)$ & \\
& 42.9 & 37.4 & 34.4 & \multirow{0}{*}{0.037} \\
Sperm concentration (million/ml) & $(24.2)$ & $(24.4)$ & $(25.3)$ & \\
\hline
\end{tabular}




\begin{tabular}{lcccc} 
Continued & & & & \\
\hline Total sperm concentration (million) & 143.2 & 118.5 & 104.6 & $>0.05$ \\
$(\mathrm{SD})$ & $(115.7)$ & $(89.8)$ & $(82.7)$ & \\
Normokinesis (\%) & 45.9 & 44.8 & 44 & $>0.05$ \\
$(\mathrm{SD})$ & $(12.3)$ & $(12.2)$ & $(15.1)$ & \\
Hypokinesis (\%) & 7.6 & 7.4 & 7.2 & $>0.05$ \\
$(\mathrm{SD})$ & $(3.7)$ & $(5.1)$ & $(4.1)$ & \\
Total motility (\%) & 53.5 & 52.2 & 51.2 & $>0.05$ \\
$(\mathrm{SD})$ & $(14.0)$ & $(15.4)$ & $(17.4)$ & \\
\hline
\end{tabular}

Kruskal Wallis test was used for comparison between groups. $\mathrm{N}=$ number.

\section{Discussion}

This is the first contemporary study to assess the quality of semen of healthy men from the general population of Bulgaria. We found that only $27.6 \%$ of the participants showed normal semen parameters. For comparison, in Spain, L Teijon et al. reported that small part of their subjects had Normozoospermia-22\% [10]. In Nigeria, Owolabi et al. documented very high percentage of normozoospermic male partners of infertile couples - 68.2\% [11]. Very large part of our subjects (46.9\%) had only morphological semen abnormalities which implies that sperm morphology is the most common abnormal parameter. The distribution of cases is a scarce statistic and therefore we couldn't find appropriate studies to which we can compare our results. Most studies focus around sperm parameters' raw data without classifying the participants further based on the results. Azoospermia was presented in $1.66 \%$ of our study subjects which is lower than the 6.2\% reported in Nigeria [11] and 5.30\% in France [12]. Regarding other semen abnormalities we didn't find appropriate studies to compare with because those studies that indeed had distribution of cases were using very different patient selection thus making juxtaposing questionable.

With respect to semen parameters again we tried to find appropriate studies for comparison. However, each study has its own methods, statistics and frequently-different patient selection criteria. All of the aforementioned facts make juxtaposing unreliable. Moreover, there are not many studies that evaluate the semen quality in a certain region based on men from the general population. Most studies like those originating from the Baltic countries focus around very young men, neglecting those over 20 years old [13]. Although these studies are very well conducted and follow almost the same pattern, they give information regarding the younger part of the population. Their study model has been used in other countries too due to its fine structure [5] [6]. These studies, based on a same model are easily comparable and they underline the difference in semen parameters between men from different countries. Other studies focus on patients with infertility or those that are proven fertile [4].

In Table 4 we have presented the results from various studies that underline the geographical difference in semen quality. In the table are included studies encompassing only men from the general population with unknown fertility as 
Table 4. Studies, assessing general semen quality in a certain region.

\begin{tabular}{|c|c|c|c|c|c|c|c|c|c|}
\hline Study & $\begin{array}{l}\text { Sample } \\
\text { size }\end{array}$ & Region & $\begin{array}{c}\text { Age } \\
\text { (years) }\end{array}$ & $\begin{array}{l}\text { Volume } \\
\text { (ml) }\end{array}$ & $\begin{array}{c}\text { Sperm } \\
\text { concentration } \\
(\text { million } / \mathrm{ml})\end{array}$ & $\begin{array}{l}\text { Total sperm } \\
\text { concentration } \\
\text { (million) }\end{array}$ & $\begin{array}{c}\text { Normokinesis } \\
\text { (\%) }\end{array}$ & $\begin{array}{l}\text { Total sperm } \\
\text { motility } \\
(\%)\end{array}$ & $\begin{array}{c}\text { Morphology } \\
\text { (\%) }\end{array}$ \\
\hline \multirow{2}{*}{$\begin{array}{l}\text { Artur Wdowiak et al. } \\
\qquad(2016)(16)\end{array}$} & 3266 & Poland & 32.28 & - & 36.33 & 145.69 & 19.48 & - & 16.65 \\
\hline & 3012 & Ukraine & 32.93 & - & 36.02 & 123.75 & 27.43 & - & 24.36 \\
\hline Jiang et al. (2013) (17) & 28,213 & China (Sichuan) & 32 & 2.5 & 65.6 & - & 38.4 & 53.8 & 9.5 \\
\hline Li et al. (2007) (18) & 1346 & $\begin{array}{c}\text { China } \\
\text { (Chongqing) }\end{array}$ & $20-40^{b}$ & 2.5 & 84.8 & 203.2 & 51.5 & 67.3 & - \\
\hline \multirow{2}{*}{$\begin{array}{c}\text { Paasch et al. (2007) } \\
\text { (6) }\end{array}$} & 457 & Germany (Leipzig) & 18.9 & 2.7 & 65 & 166 & - & 77 & 8.3 \\
\hline & 334 & $\begin{array}{l}\text { Germany } \\
\text { (Hamburg) }\end{array}$ & 19.7 & 3.4 & 63 & 206 & - & 66 & 9.3 \\
\hline $\begin{array}{l}\text { Jónrit Halling et al. } \\
\text { (2013) (19) }\end{array}$ & 481 & Faroe Islands & 24 & 4.1 & 57 & 215 & - & 64 & 6.9 \\
\hline $\begin{array}{l}\text { Mendiola et al. (2012) } \\
\qquad(20)\end{array}$ & 215 & Spain (Murcia) & 19.2 & 3.3 & 52.1 & 154 & - & 56.5 & 10.3 \\
\hline Cok et al. (2015) (21) & 658 & Turkey & $18-30^{\mathrm{b}}$ & 4.1 & 75.34 & 286.76 & 64 & 64.8 & - \\
\hline $\begin{array}{l}\text { Axelsson et al. (2011) } \\
\qquad(22)^{\mathrm{a}}\end{array}$ & 295 & Sweden & 18 & 2.9 & 71 & 210 & 53 & - & - \\
\hline $\begin{array}{l}\text { Jørgensen et al. (2012) } \\
\qquad(23)^{\mathrm{a}}\end{array}$ & 1274 & $\begin{array}{c}\text { Denmark } \\
\text { (Copenhagen) }\end{array}$ & 19.0 & 3.6 & 62 & 206 & 57 & 65 & 7.5 \\
\hline
\end{tabular}

${ }^{a}$ As some studies include patient cohorts from different years with/without a total mean data, we have included only the results for the most recent cohorts. ${ }^{b}$ No mean data available, values presented as lowest to highest.

this was our selection criteria. Although there are differences in the methods between the studies, the results we obtained here are some of the lowest reported which questions the lifestyle and the health status of Bulgarian males. When comparing mean sperm concentration per $\mathrm{ml}$ it was found that from the data we had obtained only in Poland and Ukraine had been reported lower mean data [14]. Data from Germany (Paasch et al., 2008), China [15] [16], Faroe Islands [17], Spain [18], Turkey [19], Sweden [20] and Denmark [21] were all higher when comparing both types of sperm concentration to our findings. Some of the studies showed significantly higher parameters compared to our findings. Mean semen volume varies between studies, ranging from $2.5 \mathrm{ml}$ to $4.1 \mathrm{ml}$ (Table 4) while in our study we reported a mean of $3.29 \mathrm{ml}$. Many investigators do not include normokinetic and hypokinetic spermatozoa, but prefer to measure the total motility in their studies [16] [17]. Our mean data of this parameter was 52.5\% which was lower than the values reported from Faroe Islands, China, Germany, Murcia, Turkey and Denmark however it was higher than the Barcelona study (Table 4). From the studies that indeed included normokinetic parameter, our mean value of $44.7 \%$ was lower than all reported with the exception of the study of Wdowiak [14]. In terms of morphology, we report 9.6\% normal forms which is an average value compared to the studies. We must note that in all studies we had included in our comparison table, semen analysis was manually performed 
without CASA (Computer Assisted Semen Analysis). Overall our results seem to be lower than those reported elsewhere, especially when talking about sperm concentration and motility. This fact needs more investigation as we really need to know the possible causes, because it is estimated that up to $15 \%$ of male's genome is connected to fecundity and reproductive problems may reveal other health impairments [22]. For example, DNA repair mechanisms failure is connected to increased likelihood of carcinogenesis [23].

Along with the evaluation of semen quality in Bulgarians we also examined the effect of tobacco and BMI on semen quality. There are numerous studies on this subject with mixed conclusions as some say that smoking does indeed worsen semen characteristics [24], but others say it does not [16]. According to our results, smoking does not have statistically significant effect on semen quality, although these results should be interpreted with caution due to the relatively small sample size.

The effect of BMI on semen quality is well studied although the results are not consistent. Keskin et al. in 2016 reported that BMI is not connected to semen parameters [25]. On the contrary, Andersen et al. in 2015 stated that BMI has a negative effect on semen quality, especially in males with BMI over 35 [26]. Our results imply that higher BMI is correlated with lower semen concentration per ml. Other parameters did not show statistical difference despite the obvious higher parameters in Group 1 (Table 3).

We believe that due to our inclusion criteria, the participants in this study are representatives of the general population of Bulgaria; however our results should be confirmed or questioned by other larger studies in the future in order to definitely confirm this statement.

As a possible drawback to our study is the lack of external quality control, used in other studies [6]. Other possible causes of limitations could be that only one sample was analyzed per subject. Another source of possible drawbacks is connected to the reluctancy of some participants to give more information about their lifestyle and fertility problems; however this problem can't be avoided.

Hopefully, the results from this study would underline the difference between semen characteristics among different geographical regions and urge for more research on this topic.

\section{Conclusion}

This is the first study, reporting semen quality in Bulgaria. Mean semen characteristics were lower than most of the data reported in other studies. Adverse semen parameters in Bulgaria are probably connected to the lifestyle of men and to the amount of stress they cope with. Moreover, the quality of life in Bulgaria is not that high when compared to other European countries. Furthermore, here we confirm that there are indeed differences in semen quality between different regions. We did not find a negative effect of tobacco smoking on semen quality. Higher BMI is connected to lower sperm concentration per $\mathrm{ml}$. 


\section{Acknowledgements}

We would like to express our gratitude to all people who contributed to this study.

\section{Financial Support}

This research did not receive any specific grant from funding agencies in the public, commercial, or not-for-profit sectors.

\section{Presented at a Meeting}

20th National Congress of Infertility and Reproductive Health, Borovets, Bulgaria, March 7 to 10, 2019.

\section{Conflicts of Interest}

The authors declare that they have no conflicts of interest.

\section{References}

[1] Nogueira, C., Yoshida, I.H., Vilarino, F.L., De Carvalho, W.P., Cordts, B. and Barbosa, C.P. (2018) Seminal Profile of 23,504 Patients over the Years: 7 Years of Experience. JBRA Assisted Reproduction, 22, 286-288.

https://doi.org/10.5935/1518-0557.20180055

[2] Practice Committee of the American Society for Reproductive Medicine (2012) Diagnostic Evaluation of the Infertile Male: A Committee Opinion. Fertility and Sterility, 98, 294-301. https://doi.org/10.1016/j.fertnstert.2012.05.033

[3] Carlsen, E., Giwercman, A., Keiding, N., Skakkeblek, N.E. and Skakkebsk, N.E. (1992) Evidence for Decreasing Quality of Semen during Past 50 Years. BMJ, 305, 609-613. https://doi.org/10.1136/bmj.305.6854.609

[4] Elbardisi, H., et al. (2018) Geographical Differences in Semen Characteristics of 13892 Infertile Men. Arab Journal of Urology, 16, 3-9. https://doi.org/10.1016/j.aju.2017.11.018

[5] Fernandez, M., et al. (2012) Semen Quality and Reproductive Hormone Levels in Men from Southern Spain. International Journal of Andrology, 35, 1-10. https://doi.org/10.1111/j.1365-2605.2010.01131.x

[6] Paasch, U., et al. (2008) Semen Quality in Sub-Fertile Range for a Significant Proportion of Young Men from the General German Population: A Coordinated, Controlled Study of 791 Men from Hamburg and Leipzig. International Journal of Andrology, 31, 93-102. https://doi.org/10.1111/j.1365-2605.2007.00860.x

[7] Virtanen, H.E., Jørgensen, N. and Toppari, J. (2017) Semen Quality in the 21st Century. Nature Reviews Urology, 14, 120. https://doi.org/10.1038/nrurol.2016.261

[8] WHO (2010) WHO Laboratory Manual for the Examination and Processing of Human Semen. 5th Edition, WHO, Geneva.

[9] WHO (1999) WHO Laboratory Manual for the Examination of Human Semen and Sperm-Cervical Mucus Interaction. 4th Edition, Cambridge University Press, Cambridge.

[10] López-Teijón, M. (2007) Semen Quality in a Population of Volunteers from the Province of Barcelona. Reproductive BioMedicine Online, 15, 434-444. 
https://doi.org/10.1016/S1472-6483(10)60370-7

[11] Owolabi, A.T., Fasubaa, O.B. and Ogunniyi, S.O. (2013) Semen Quality of Male Partners of Infertile Couples in Ile-Ife, Nigeria. Nigerian Journal of Clinical Practice, 16, 37-40. https://doi.org/10.4103/1119-3077.106729

[12] Geoffroy-Siraudin, C., Loundou, A., Romain, F., Achard, V., Courbiere, B. and Perrard, M.-H. (2012) Decline of Semen Quality among 10932 Males Consulting for Couple Infertility. Asian Journal of Andrology, 14, 548-590. https://doi.org/10.1038/aja.2011.173

[13] Jørgensen, N., et al. (2002) East-West Gradient in Semen Quality in the Nordic-Baltic Area: A Study of Men from the General Population in Denmark, Norway, Estonia and Finland. Human Reproduction, 17, 2199-2208. https://doi.org/10.1093/humrep/17.8.2199

[14] Wdowiak, A., Wdowiak, A., Moroz, E. and Bojar, I. (2016) Comparison of Selected Sperm Parameters between 6,278 Males in Poland and Ukraine. Annals of Agricultural and Environmental Medicine, 23, 174-181. https://doi.org/10.5604/12321966.1196876

[15] Jiang, M., et al. (2014) Semen Quality Evaluation in a Cohort of 28213 Adult Males from Sichuan Area of South-West China. First International Journal of Andrology, 46, 842-847. https://doi.org/10.1111/and.12168

[16] Li, Y., et al. (2009) Semen Quality of 1346 Healthy Men, Results from the Chongqing Area of Southwest China. Human Reproduction, 24, 459-469. https://doi.org/10.1093/humrep/den399

[17] Halling, J., Petersen, M.S., Jørgensen, N., Jensen, T.K., Grandjean, P. and Weihe, P. (2013) Semen Quality and Reproductive Hormones in Faroese Men: A Cross-Sectional Population-Based Study of 481 Men. BMJ Open, 3, e001946. https://doi.org/10.1136/bmjopen-2012-001946

[18] Mendiola, J., et al. (2013) Sperm Counts May Have Declined in Young University Students in Southern Spain. Andrology, 1, 408-413. https://doi.org/10.1111/j.2047-2927.2012.00058.x

[19] Cok, I., Karababa, G., Şatıroğlu, M.H., Çakmak Pehlivanlı, A., Göney, G. and Çiftçi, U. (2015) Semen Quality in 24693 Turkish Men over a 16 Year Period (1995-2011). Hacettepe Journal of Biology and Chemistry, 43, 33-41.

[20] Axelsson, J., Rylander, L. and Giwercman, A. (2011) No Secular Trend over the Last Decade in Sperm Counts among Swedish Men from the General Population. $\mathrm{Hu}$ man Reproduction, 26, 1012-1016. https://doi.org/10.1093/humrep/der045

[21] Jørgensen, N., et al. (2012) Human Semen Quality in the New Millennium: A Prospective Cross-Sectional Population-Based Study of 4867 Men. BMJ Open, 2, e000990. https://doi.org/10.1136/bmjopen-2012-000990

[22] Matzuk, M.M. and Lamb, D. (2008) The Biology of Infertility: Research Advances and Clinical Challenges. Nature Medicine, 14, 1197-1213. https://doi.org/10.1038/nm.f.1895

[23] Mukherjee, S., Ridgeway, A. and Lamb, D. (2010) DNA Mismatch Repair and Infertility. Current Opinion in Urology, 20, 525-532. https://doi.org/10.1097/MOU.0b013e32833f1c21

[24] Sharma, R., Harlev, A., Agarwal, A., Esteves, S.C. and Gratzke, C. (2016) Cigarette Smoking and Semen Quality: A New Meta-Analysis Examining the Effect of the 2010 World Health Organization Laboratory Methods for the Examination of $\mathrm{Hu}$ man Semen. European Urology, 40, 635-645. 
https://doi.org/10.1016/j.eururo.2016.04.010

[25] Keskin, M.Z., et al. (2017) Investigation of the Effect of Body Mass Index (BMI) on Semen Parameters and Male Reproductive System Hormones. Archivio Italiano di Urologia e Andrologia, 89, 219. https://doi.org/10.4081/aiua.2017.3.219

[26] Andersen, J., et al. (2015) Body Mass Index Is Associated with Impaired Semen Characteristics and Reduced Levels of Anti-Müllerian Hormone across a Wide Weight Range. PLoS ONE, 10, e0130210.

https://doi.org/10.1371/journal.pone.0130210 